\title{
The Exploration of Hazard Prediction Techniques and Security Manage- ment Strategies for Domestic Road Construction
}

\author{
Chenhao Guo ${ }^{1, *}$, Yapeng Yan $^{2}$ and Tiansong Wang ${ }^{3}$ \\ ${ }^{1}$ School of Materials Science and Engineering, Chang' an University, Xi'an 710064, China; ${ }^{2}$ CCCC First Highway Con- \\ sultants Co., Ltd, Xi'an 710075, China; ${ }^{3}$ Shanxi Municipal Building Design Institute Co., Ltd, Xi'an 710075, China
}

\begin{abstract}
With the rapid development of the economy in China and the speeding up of urbanization, urban roads and highways in China continue to increase. However, due to some of the characteristics of road construction, long duration, high fluidity, large volume of work and complex process, there exist many security problems during the period of construction, which determines that security management is unoptimistic on construction site. This paper makes a comprehensive research over the achievements of domestic and foreign experts and analyzes the causes of the security incidents in domestic road construction, so as to further clarify that the deep reasons for the security incidents in management. Based on this, the author advances the corresponding security management measures. With comprehensive evaluation methods applied on road construction site, the security situation can be predicted and prevented whenever and wherever possible.
\end{abstract}

Keywords: Domestic road construction, evaluation methods, management measure, security incidents.

\section{INTRODUCTION}

The security management of construction industry has been attached greatest importance in the whole society. In order to respond to the national slogan "safety first", construction industries should not only rethink and analyze the existing problems in road construction, but also conduct an intensive study on the factors threatening road construction security and then put forward to a relevant management policy.

In the development process of safety management, security management mainly experienced three stages. The first stage developed from the early after-accident management to preventive management, safety management work of this stage is mainly passive safety technical management. The second stage developed from the modern accident management to modern risk management, safety management work of this stage mainly depends on the strict safety supervision method with emphasis on standardization and standardized management. The third stage developed from the accident cause theory to modern scientific system of management, safety management work of stage advocates "peopleoriented" scientific system of management and safety consciousness [1].

\section{CURRENT SITUATION OF ROAD CONSTRUC- TION SECURITY MANAGEMENT}

\subsection{Connotation of Security Management}

Security management is the modernized and scientific management for the purpose of security in the production process. In accordance with the requirements of the relevant state policies and regulations and on the basis of the actual situation in enterprises, the basic task of security management is to establish a long-term management mechanism for enterprise security production, standardize the operation activities in enterprise operation process and take relevant safety management measures, in order to scientifically foresight, proactively find and effectively control the dangerous and harmful factors in the process of production, then formulate corresponding security technical measures and security management system, so as to take the initiative to prevent and control the occurrence of accidents and occupational diseases and reduce the losses caused by security incidents [2].

\subsection{The Necessity to Reinforce Security Management of Road Construction}

Along with the reform and opening up and especially the increasing investment in highway construction in our country since 1990s, the national roads has been developing rapidly, which forms a comparatively perfect road construction network.At present, the engineering amount of domestic road construction is large, at the same time, a large number of construction security accidents have occurred. Therefore, it is very important to do analysis in road engineering construction in order to find the causes of the security accidents.

\subsection{The Main Types of Road Construction Accident}

Road engineering construction is a complicated system with man, machine and environment involved, which has characteristics of multiple spots, long term, long construction period, great influence by natural conditions, and frequent security accidents. The road construction accident in China is basically concluded as the following 9 types: 
(1) falling objects (2) collapse accident (3)strike of objects (4) mechanical accident (5) vehicle damage (6) electric shock (7) fire explosion accident (8) burns and scalds (9) poisoning and suffocation, among which the former six ones are the most common types of accidents in road construction.

\subsection{The Road Construction Security Accident Cause Analysis}

Along with the development of the accident causation theory, people's understanding of the nature of the accident is also unceasingly and thoroughly improving, we can find that the personal factors, physical factors, environmental factors and management factors are the four main biggest factors causing road construction security accidents [3-5].

\subsubsection{Personal Factors}

Personal factors mainly refer to the unsafe behavior directly causing the construction accident. According to the national enterprise worker casualty classification standards, the unsafe behavior of people can be divided into 10 categories.

\section{Operational error}

2. Safety device failure

3. Use of unsafe equipment

4. Manual operation without tools

5. Improper storage of materials

6. Venturing into dangerous places

7. Climbing unsafe places

8. Staying and working under the lifting objects

9. Maintaining when machine is operating

10. Distraction at work

11.Improper use of protective equipment

12. Wearing unsafe clothes

13.Incorrectprocessing of explosive dangerous goods

\subsubsection{Physical Factors}

In road construction process, the physical factor refers to the unsafe state of objects, namely mechanical equipment and construction materials completely do not meet the requirements of safety state, which is also one of the direct factors leading to construction accident. The unsafe states of the main properties include the defects of properties, improper storage method, incorrect construction methods and the absence of safety signs, etc. All of the unsafe states of objects are caused by the unsafe behaviors, operations, management mistakes of people [6, 7].

\subsubsection{Environment Factor}

Environment factors refer to the adverse states surrounding the road construction site. The adverse road construction environment will not only influence people's behavior but also have adverse effect on construction materials, which is easy to lead the construction accidents. As is known to all, the distinctive features of road construction project are outdoor working, various operations, much cross operation, low degree of mechanization and various materials, etc., many variable factors are likely to affect the working environment, and even have a significant impact on the safety of road construction [8-10].

\subsubsection{Management Factor}

People's unsafe behavior and unsafe state of the objects are just the surface reason for safety. Management factors leading to safety accident mainly include: enterprise leaders' indifference of construction safety, weak safety consciousness, imperfect safety management mechanism, unclear responsibility, unsound safety management system, construction organization and safety operating rules, unreasonable safety technical measures, insufficient safety investment and efforts in education and training and incomplete safety rectification to hidden perils, etc.

\section{THE IDENTIFICATION AND EVALUATION OF ROAD CONSTRUCTION HAZARD}

\subsection{The Constituent Elements and Classification of Haz- ards}

\subsubsection{The Constituent Elements of Hazards}

According to the definition of hazard, hazards are the cause of all safety accidents, which should have three basic elements: (1) the potential danger, (2) the existence condition, (3) the trigger factors (including personal factors, natural factors and management factors).

\subsubsection{The Theoretical Classification of Hazards}

According to classification and code for danger and hazard in production process, hazards that exist in the road construction process can be divided into biological hazards, behavioral hazard, physical hazards, chemical hazards and psychological hazards

\subsection{Hazard Identification}

Hazard identification is the basis of hazard control and is one of the key measures of hazards control, which can provide guarantee for hazard control. Hazards identification content mainly includes: the working environment; layout; transportation lines; construction process; construction machinery and equipment; hazardous work area and all kinds of facilities.

\subsubsection{The Identification Method of Hazard}

\subsubsection{Intuitive Experience Method}

Intuitive experience method, as commonly-used method in the identification of hazards, shows its advantage in simplicity and easiness, but sees its disadvantage in the limitation of identification knowledge and experience of personnel. Intuitive experience method mainly covers contrast analysis method, experience method and analogy inference method, etc.

\subsubsection{The System Safety Analvsis Method}

System safety analysis method is commonly used in the complex system or newly developed system without accident experience, which can be widely used in different fields, stages and occasions. At present, the system safety analysis 


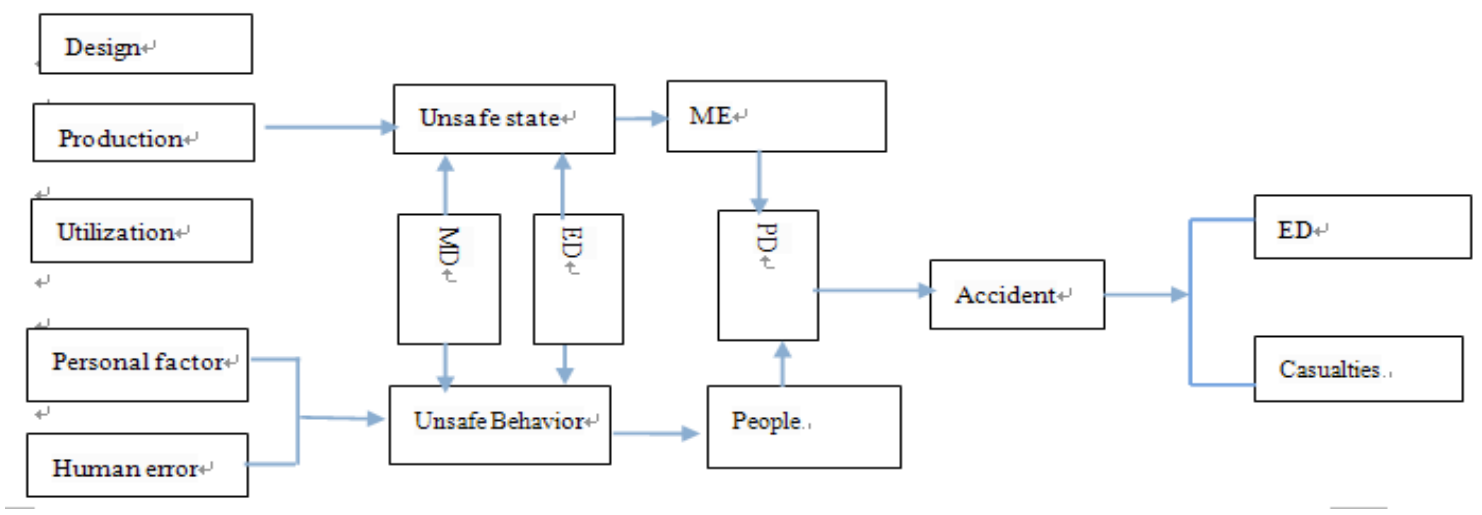

Fig. (1). Hazards in road construction.

MD_-Management Defect; ED—Environment Defect; ME—-Mechanical Equipment; PD—Potential Danger; MED—— Mechanical Equipment Defect

method applicable for the road construction project is safety check list, risk analysis, fault tree analysis (FTA), event tree analysis (ETA) and causal analysis, etc. In the hazard identification of road construction project process, all these methods can be used together.

\subsection{The Relevant Preventive Techniques of hazards in Road Construction}

Therefore, based on the accident causes analysis in the road construction, this paper proposes the preventive techniques of hazards from the following four aspects. The hazards in road construction are listed in Fig. (1).

\subsubsection{Safety Management of People}

The safety management of people is to control humancaused error and reduce the trigger effect of incorrect behavior on hazards. To control people's unsafe behavior, the foremost thing to do is to have a reasonable personnel placement and arrangement because hazards mostly come from the important positions. Secondly, safety culture establishment in construction enterprise should be strengthened. The strict training and assessment should be conducted among personnel.

\subsubsection{Machinery and Equipment Safety Management}

The management control mode of unsafe state of machinery and equipment can be prevented by formulating and perfecting the operation procedures, construction technology and solutions, etc., The adoption of new technology, application of new equipment, increase of the safety investment and safety facilities configuration, reasonable arrangement and improvement of safety facilities and operating conditions, focus on the safety management and monitoring of the equipment, and regular maintenance inspection facilities can avoid the trajectory of unsafe state of objects meeting with unsafe behavior of people.

\subsubsection{The Construction Environment Safety Management}

The working environment is directly related to road construction safety management. The core of the working environment is how to maintain clean, orderly and safe working environment, creating a good working environment for the personnel.
(1) Construction plane layout.

(2) Functional zone division in the construction site.

(3) Safety warning signs.

(4) Regular safety evaluation. for operational environment.

\subsubsection{The Safety Management of Management System}

In the process of road construction, the following measures can be adopted to control and manage the hazards in order to achieve the goal of construction security.

1. Establish and improve the hazard management rules and regulations.

2. Put the regular examination of hazard at all levels into practice.

3. Strengthen the daily management of hazard to ensure personnel to carry out daily management rules and regulations of relevant hazards.

4. Rectify and reform hidden danger in time according to the information feedback.

5. Pay special attention to the infrastructure work of hazard control and management to carry out archive management on the hazards.

6. Carry out the system of rewards and punishments on hazard control and management.

7. Set up level-to-level management system of hazard to take tracking management of dynamic hazards.

8. Formulate corresponding contingency plans for the major hazards.

\section{THE PREVENTIVE MANAGEMENT MODE FOR ROAD CONSTRUCTION SECURITY}

\subsection{The Principle of Road Construction Security Control and Management}

The American engineer Heinrich proposed the famous causal chain theory of accident in his Prevention of Industrial Accident, which is shown in Fig. (2). 


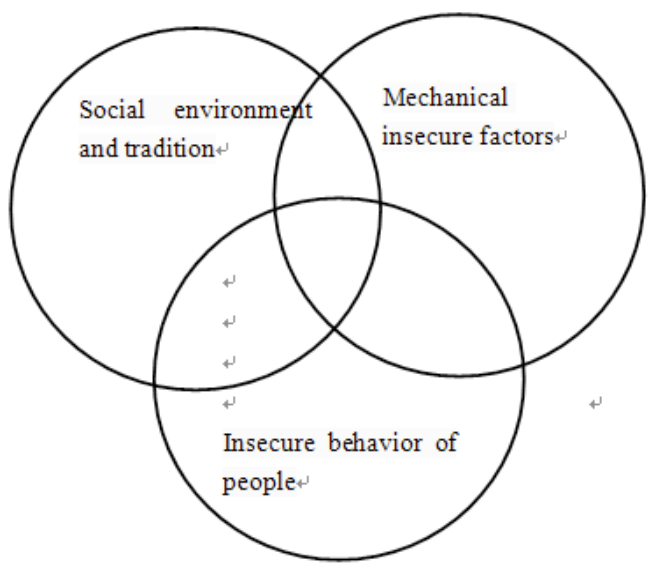

Fig. (2). Causal Chain Theory of Accident.

Heinrich expounded causal chain theory of accident in his Prevention of Industrial Accident, and analyzed the problem of people and objects in cause of accident, relationship between the accident frequency and severity of injury, the causes of unsafe behavior of people, the relationship between safety management and enterprise management, basic responsibility of safety management and control work and the relationship between the safety production and safety management.

\subsection{Main Content of Preventive Management Activities in Road Construction}

\subsubsection{Daily Safety Management}

All responsible for the safety must have a corresponding experience and fire prevention knowledge in safety construction, or have engaged in safety work for years. The concrete security system which needs to implement are listed in Fig. (3).

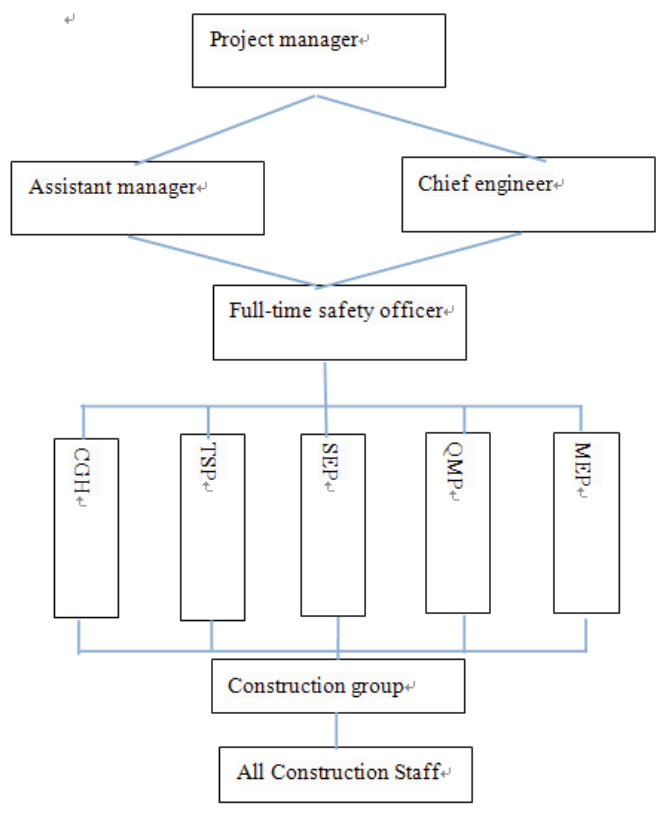

Fig. (3). The concrete security system.

CGA_Construction Group Head; TSP_— Traffic Safety Principal; SEP_—Safety Equipment Principal; QMP_— ty Management Principal; MEP_—nical Equipment Principal.

\subsubsection{Accident Emergency Rescue}

The accident emergency rescue system designed in the safety organization system of is an important part. So, the accident emergency rescue can be processed as follows in Fig. (3).

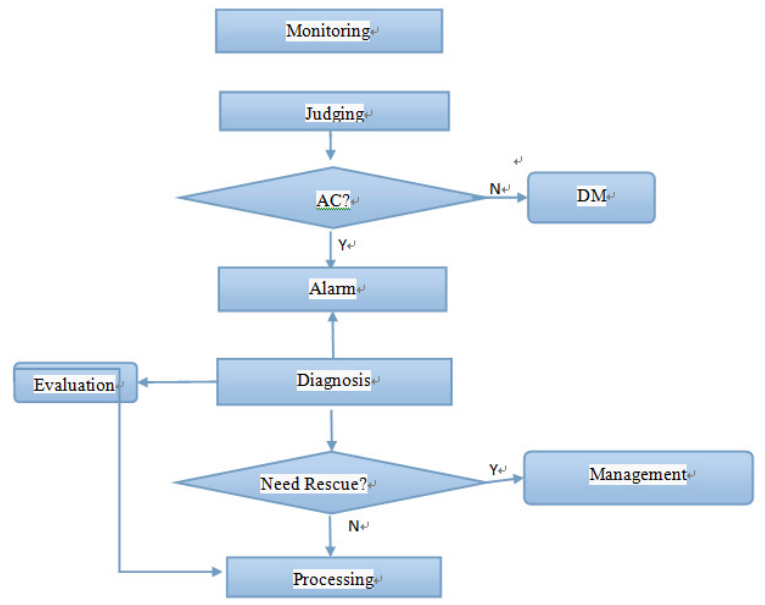

Fig. (3). Road construction safety management model.

$\mathrm{AC} \_$Abnormal Condition; DM_-Daily Management

The reporting procedures of accident emergency rescue organizations are as follows in Fig. (4):

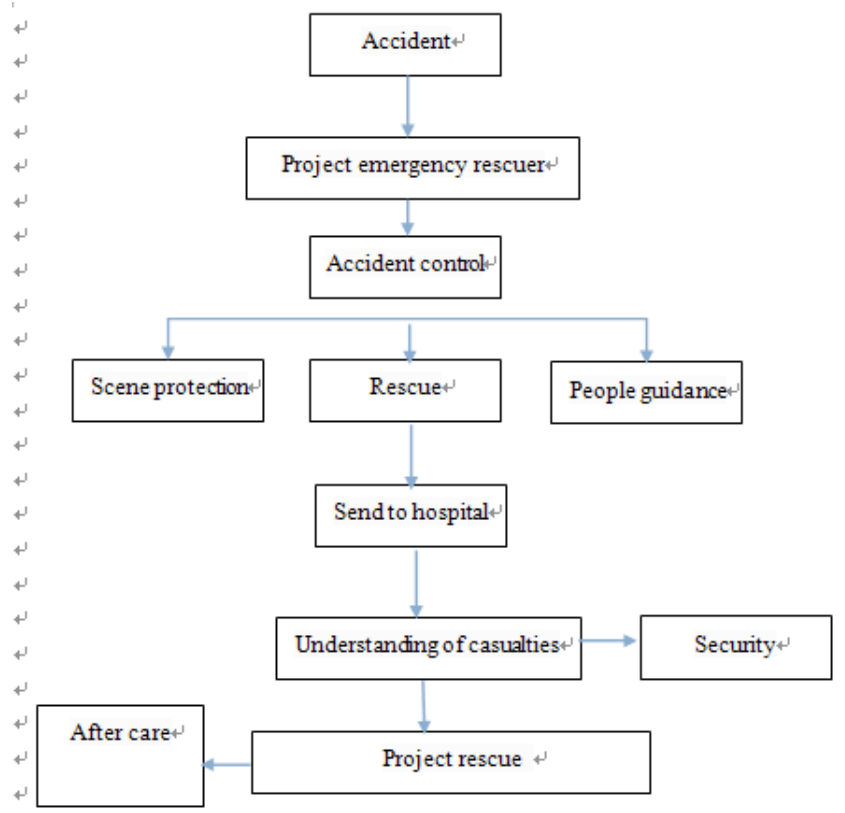

Fig. (4). The emergency rescue procedures of road construction accident.

\subsection{The safety management measures in road construc- tion}

\subsubsection{Safety Management Institutions and Personnel}

Safety production law regulates that mine, construction unit and unit of production, management and storage of dangerous goods shall set up safety production management institutions or equip with full-time safety management per- 
sonnel. In other production and business operation entities with the staff number of more than 300 , safety production management institution shall be erected and full-time safety management personnel should be equipped with.

\subsubsection{Safety Training Education Andexamination}

The safety education and training work in road construction enterprises is the important method to improve the employees' safety consciousness and safety technical quality, prevent people's unsafe behavior and reduce the construction accident. Especially for the front-line operator education, whose technical quality is relatively poor and legal consciousness is relatively lower, thus to strengthen safety education, road construction enterprises should conform to three principles: avoidance of internal harm, eternal harm and mutual harm.

\subsubsection{Mechanical Road Constructionequipment}

In recent years, road construction in many parts of China implements fast curing method with mechanical construction equipment of high efficiency and high technical content, which is beneficial to improving the efficiency and quality of road construction, reducing the number of road construction personnel and the probability of traffic accident.

\subsubsection{Construction Information Release}

According to the characteristics of expansion project of the road construction, the special design in terms of traffic safety facilities and construction information should be displayed and released. Meanwhile, the static and dynamic safety facilities, the common and electronic security facilities, organic graphics and sound warning and safety facilities should be reasonably combined and displayed, which can make drivers timely grasp the abnormal traffic information in road construction process, thus, the relevant road construction accident can be avoided as a matter of course.

\section{CONCLUSION}

It is of great risk to do pavement construction in many areas of China, therefore, if the safety management is not given much emphasis, it will not only hurt the construction workers who have suffered the disaster in the event of accidents and pose a great misfortune to their family members, but also the road construction enterprise shutdown to take rectification and pay a huge sum of economic compensation, which is bound to affect the image and economic benefits of the road construction enterprise. What's worse, it will have a great impact on the road construction employees and lead to their depression in mood and low work enthusiasm. There- fore, safety production is of great responsibility in many aspects. Since the safety management of road construction is a complex task and safety construction covers a lot of grounds, the road construction enterprises need to do a good job in all kinds of safety management activities to meet the requirements of road safety construction. Relevant departments should give a clear understanding to their particularity and strengthen the understanding of safety production and management. Only in this way can the safety of road construction be guaranteed.With the help of road construction accident management system, the monitoring, diagnosis and control of hazard and accident in road construction can be successfully done in advance, thus the loss from the road construction accidents can be minimized as far as possible.

\section{CONFLICT OF INTEREST}

The authors confirm that this article content has no conflict of interest.

\section{ACKNOWLEDGEMENTS}

Declared none.

\section{REFERENCES}

[1] H. W. Henrich, D. Petersen and N. Roose, "Industrical Accident Prevention," 5th ed. New York, McGraw-Hi 11, 1980.

[2] J. Hinze, and G. Wilson, "Moving Toward A Zero Injusry OSjective," Journal of constructing Engineering and Management, vol. $10,2000$.

[3] R. S. Harper, and E, Koehn, "Managing Industrial Construction Safety In Southeast Texas," Journal of Construction Engineering and Management, vol. 124, no. 6, pp. 452-457, 1998.

[4] S. Lee and D. W. Halpin, "Predictive Tool for Estimating Accident Risk," Journal of Construction Engineering and Management, vol. 128, no. 4, pp. 452-457, 2003.

[5] M. Sugeno, and T. Yasukawa, "A fuzzy-logic-Sased approach to qualitative modeling," IEEE trans. On Fuzzy System, vol. 1, no. 1, pp. 1993.

[6] S. Tian, C. Feng, and D. Wang, "Three-Safety-hands theory and safety science Architecture [A]. Progress in safety science and technology proceedings technology of the 2000 international symposium on safety science: the and," Beijing: Published by Chemical Industry Press, 2000.

[7] D. Wen, "Highway construction safety technology," Beijing: China communication press, 2003.

[8] The annual safety analysis. Government network of safety supervision administration[OL]http://www.china.safety.gov.cn, 2007.

[9] The bloody safety accident. China Road, no. 4, 2006.

[10] In Hunan Fenghuang County dike creek bridge collapse accident, over 64 people were killed after rescue work [OL]. Government network of safety supervision administration. http://www.chinasafety. gov.cn.2007.

Received: February 03, 2015

Revised: April 03, 2015

Accepted: May 25, 2015

(C) Guo et al.; Licensee Bentham Open.

This is an open access article licensed under the terms of the (https://creativecommons.org/licenses/by/4.0/legalcode), which permits unrestricted, noncommercial use, distribution and reproduction in any medium, provided the work is properly cited. 